Article

\title{
Negative Self-Assessment of Health in Women: Association with Sociodemographic Characteristics, Physical Inactivity and Multimorbidity
}

Thays Angélica de Pinho Santos ${ }^{1,2}$, Rafael Alves Guimarães ${ }^{2}$ *, Valéria Pagotto ${ }^{2}$, Natália Del' Angelo Aredes ${ }^{2}$, Isabela Silva Levindo de Siqueira ${ }^{3} \mathbb{D}$, Suiany Dias Rocha ${ }^{4}$, Clarissa Irineu de Sousa Carrijo ${ }^{2}$ and Claci Fátima Weirich Rosso ${ }^{2}$

check for updates

Citation: Santos, T.A.d.P.; Guimarães, R.A.; Pagotto, V.; Aredes, N.D.A.; Siqueira, I.S.L.d.; Rocha, S.D.; Carrijo, C.I.d.S.; Rosso, C.F.W. Negative Self-Assessment of Health in Women: Association with Sociodemographic Characteristics, Physical Inactivity and Multimorbidity. Int. J. Environ. Res. Public Health 2022, 19, 2666 https://doi.org/10.3390/ ijerph19052666

Academic Editor: Paul B. Tchounwou

Received: 14 December 2021 Accepted: 8 February 2022

Published: 25 February 2022

Publisher's Note: MDPI stays neutral with regard to jurisdictional claims in published maps and institutional affiliations.

Copyright: (C) 2022 by the authors. Licensee MDPI, Basel, Switzerland. This article is an open access article distributed under the terms and conditions of the Creative Commons Attribution (CC BY) license (https:// creativecommons.org/licenses/by/ $4.0 /)$.
1 Federal Institute of Education, Science and Technology of Goiás, Campus Goiânia Oeste, Goiânia 74055-110, Goiás, Brazil; thayssantos.ifg@gmail.com

2 Faculty of Nursing, Federal University of Goiás, Goiânia 74605-080, Goiás, Brazil; valeriapagotto@ufg.br (V.P.); naredes@ufg.br (N.D.A.A.); clarissa.carrijo@ufg.br (C.I.d.S.C.); claci@ufg.br (C.F.W.R.)

3 School of Social and Health Sciences, Pontifical Catholic University of Goiás, Goiânia 74605-010, Goiás, Brazil; isabelalevindo@gmail.com

4 Municipal Department of Education, Goiânia 74610-155, Goiás, Brazil; suianydias@gmail.com

* Correspondence: rafaelalves@ufg.br

\begin{abstract}
Introduction: Women present a higher prevalence of negative self-assessment of health (NSAH) when compared to men. However, there is a gap in the literature of factors associated with NSAH in women from developing countries such as Brazil. In addition, few studies have assessed the magnitude of the association between multimorbidity and NSAH in this population. Thus, the aim of this study was to evaluate the association between NSAH and sociodemographic characteristics, lifestyle and multimorbidity in women from the Midwest region of Brazil. Methods: A study based on data from the National Health Survey, a household survey that investigated health situation, lifestyle and risk factors for chronic diseases in the adult population of Brazil, was held. Sampling was performed in multiple stages. The selected women answered a standardized questionnaire on sociodemographic data, self-assessment of health and potential determinants. Poisson regression was used to analyze the association between NSAH and sociodemographic characteristics, lifestyle and multimorbidity. A significance level of $0.05 \%$ was established. Results: The study included 4233 women. The prevalence of NSAH found was $6.0 \%$ (95\% Confidence Interval [95\% CI]: 5.1-7.0\%). There was an association between NSAH and advancing age, low schooling, physical inactivity and multimorbidity. Furthermore, there was an association between NSAH and diseases/disorders such as chronic back pain, systemic arterial hypertension, mental disorders, depression, cardiovascular diseases, stroke, cancer, hypercholesterolemia and diabetes mellitus. Conclusion: The prevalence of NSAH was low. A strong association was found between this variable and multimorbidity. In addition, increased age, low schooling and physical inactivity were predictors of NSAH in women.
\end{abstract}

Keywords: health self-assessment; chronic disease; multimorbidity; women's health; morbidity; primary care; healthy behavior

\section{Introduction}

Chronic noncommunicable diseases (NCDs) have a significant impact on public health, resulting in high morbidity and mortality, and high costs for health services and society in general [1-3]. According to the World Health Organization (WHO), the mortality rate related to NCDs has increased globally, regardless of socioeconomic factors [1]. In 2016, NCDs accounted for about $71 \%$ of deaths worldwide, most of them in low- and middle- to low-income countries [1]. Approximately 55 million deaths are expected to occur in 2030 due to complications of NCDs [4]. 
In Brazil, NCDs also have a high burden, being one of the major causes of premature death in adults $[1,5]$. It is estimated that NCDs represent $72 \%$ of the causes of death and that the probability of premature death in the country is $17 \%$ [1]. In 2016, the Global Burden of Disease (GBD) report estimated that there were 314,438 deaths from NCDs in individuals between 30 and 69 years of age, resulting in a standardized mortality rate of 340.4 deaths per 100,000 inhabitants [6].

The high burden of NCDs is due to the aging of the population and, above all, the increase in modifiable risk behaviors, such as smoking, alcohol abuse, physical inactivity, and inadequate diet, together with important social determinants in health [7]. These factors have an important impact on the reduction of functionality and are also related to the low quality of life of the population [8]. They also burden health services by increasing demand and are responsible for a large part of the countries' Gross Domestic Product (GDP) through direct and indirect costs [2].

The negative effects of NCDs are enhanced in the presence of multimorbidity. This condition is defined as the coexistence of two or more NCDs in the individual [9]. Accordingly, multimorbidity due to NCDs is increasing in low- and middle-income countries, such as Brazil, and challenging health systems [10]. Individuals with multimorbidity present a higher risk of premature mortality, decreased functioning of physical and mental health, reduced quality of life, and have an increased demand of health services [10-12].

Several studies have shown that multimorbidity is strongly associated with negative self-assessment of health (NSAH) [13-16]. This indicator is used to verify the assessment or perception that individuals have of themselves regarding their health, being essential for monitoring the health conditions of populations $[17,18]$. It is a multidimensional indicator that takes care of objective and subjective aspects, covering nuances related to social health constraints and determinants [18]. It is also known that NSAH is associated with the presence of NCDs, morbidity, mortality and is also related to the presence of risk factors as previously described in the context of NCDs [17-20]. The literature found sustain that there is an association between sedentary lifestyle and NSAH [17], reporting that $87 \%$ of women analyzed in this specific research were physically inactive. Additionally, an association between NSAH and higher index body mass (IBM) is recognized, similarly to its association with female gender [21], pointing to behavioral aspects related to women's lifestyle that must be addressed to avoid NSAH and NCDs.

Health self-assessment has a global evaluative nature, which considers several aspects of health, both subjective and objective, combined within the perceptive structure of the individual. Due to its ability to predict mortality and morbidity, health self-assessment is as an important indicator of the health status of populations. Self-assessment of health has a multidimensional structure, which comprises socioeconomic status, social support, physical health conditions, and access and use of health services, which are relevant to characterize people's health status. Thus, self-rated health may reflect the presence of multimorbidity, which increases complex and continuous demands for care, greater use of health services and eventually complications that acutely affect health. Studies shows that poorer self-rated health is a reflection of the higher burden of disease, such as hypertension [22], smoking and leisure-time physical inactivity [23], stroke, musculoskeletal and other pain disorders, and three or more diseases [24].

Women tend to have a higher prevalence of NSAH compared to men [25]. In general, Brazilian women also presented a worse landscape of NSAH compared to men [18,26]. The incidence of NSAH in one study conducted with 1339 participants was 24.0 in men and $30.0 \%$ in women [26]. A larger investigation with 59,758 participants found that $6.8 \%$ of women reported NSAH compared to $4.8 \%$ among men, and male participants presented better positive self-assessment of their health, except when compared to women with more financial resources, privileged social groups and non-participant of the workforce were considered as variables in this analysis [18]. This is caused especially by gender inequalities, in addition to the higher prevalence of physical and mental NCDs and multimorbidity in women $[18,25,27]$. However, there is a gap in the literature in developing countries [25], 
such as Brazil, on the factors associated with NSAH in women and, especially, surveys on its association with multimorbidity. Most available studies conducted analyses grouped between genders or investigated associated factors in specific subgroups (e.g., elderly), using non-representative samples and did not assess the impact of multimorbidity on NSAH.

Thus, it is essential to investigate the factors associated with NSAH in women, especially multimorbidity, so that developing countries can develop strategies and public policies for the integral care of this population, aiming at surveillance of NCDs, reduction of the magnitude of NCDs, prevention measures and increased quality of life. The aim of this study was to analyze the association between NSAH and sociodemographic characteristics, lifestyle and multimorbidity in women from the Midwest region of Brazil.

\section{Materials and Methods}

\subsection{Data Source}

This was a cross-sectional, population-based study, using the National Health Survey (Pesquisa Nacional de Saúde-PNS) conducted in 2013 as a data source. The PNS is a survey conducted by the Ministry of Health in partnership with the Oswaldo Cruz Foundation and the Brazilian Institute of Geography and Statistics (IBGE). The general objective of this survey is to characterize the health conditions of the Brazilian population, lifestyle, access and use of health services, among other aspects [28,29].

The population of the NHS was represented by adult individuals aged 18 years or older living in all regions of Brazil. The previous study presented the data in a way grouped by sex and country [19]. In the present study, we analyzed data from women living in the four states of the Midwest region of Brazil: Mato Grosso, Mato Grosso do Sul, Goiás and the Federal District.

The sampling was done by clusters in three stages. The first was composed of the Primary Sampling Units and included census tracts of the selected municipalities. The second included the Secondary Sampling Units, which included permanent private households, defined as those intended to serve as housing for one or more people. Finally, the third stage included the Tertiary Sampling Units, composed of the resident of the selected household who answered the interview. A resident person was defined as the one who remained at home for at least three days a week. In all stages, the units were selected by simple random sampling [28,29].

Data collection was performed by trained professionals using Personal Digital Assistants. The questionnaire used in the PNS was validated by specialists and included collection of multiple variables. In the present study, variables with data on sociodemographic characteristics, lifestyle and presence of self-reported NCDs were used [28,29].

\subsection{Variables}

\subsubsection{Dependent Variable}

The dependent variable was NSAH, categorized dichotomously as " 0 -No" or " 1 Yes". The primary variable used for its construction was obtained from the question "In general, how do you evaluate your health?". The response options were organized on a Likert scale: "very good", "good", "fair", "poor" or "very poor". In this study, the participant who reported poor or very poor self-rated health was considered with NSAH [30].

\subsubsection{Independent Variables}

The following independent variables were taken into account:

(i) Sociodemographic

Age group, stratified in the following groups: 18-39 years, 40-59 years and >60 years [31]; schooling (without schooling/incomplete elementary school, complete elementary school/incomplete high school, complete high school/incomplete higher education or complete higher education or higher) [19]; self-reported race/skin color, categorized as white, black, brown or others that included the indigenous and yellow categories due to 
the small number of observations in the sample [32]; marital status (with spouse or without spouse); residence area (rural or urban) and; state of residence (Goiás, Mato Grosso, Mato Grosso do Sul or Distrito Federal).

(ii) Lifestyle

(ii.1) Recommended consumption of vegetables and fruits (no or yes), defined as the daily consumption of at least $400 \mathrm{~g}$ of fruits and vegetables, which is equivalent to five portions or more a day, on five or more days of the week [33]. Consumption was measured based on questions about the frequency of ingesting raw and/or cooked vegetables and fruits: "On how many days of the week, do you usually eat lettuce and tomato salad or any other vegetable or raw vegetable?"; "In general, how many times a day do you eat this type of salad? (If Yes, in the previous answer) "; "On how many days of the week do you usually eat vegetables or cooked vegetables, such as cabbage, carrots, chayote, eggplant, zucchini? (Not counting potatoes, cassava or yams)"; "In general, how many times a day do you eat vegetables or cooked vegetables? (If Yes, in the previous answer) "; "On how many days of the week do you usually drink fresh fruit juice?"; "In general, how many glasses a day do you drink of fresh fruit juice? (If yes, in the previous answer) "; "How many days a week do you usually eat fruit?" and "On how many days of the week do you usually eat fruit? (If yes, in the previous answer." The sum of the amount of daily consumption was performed to compute the variable on a continuous basis, being considered regular consumption when the sum was equal to or greater than five.

(ii.2) Consumption of meat and/or chicken with excess fat (no or yes), individuals who reported consuming chicken with skin or meat with fat regardless of the amount consumed and weekly frequency [34]. Consumption was assessed based on the questions: "When you eat red meat, do you usually: (1. Remove the visible excess fat/2. Eat with fat)?", and "When you eat chicken, do you usually: (1. Remove the skin/2. Eat with the skin)?".

(ii.3) Regular consumption of sweets (no or yes). Those who reported consuming sweets on five or more days of the week were taken into account [34]. This was obtained from the question: "On how many days of the week do you eat sweet foods, such as slices of cake or tart, sweets, chocolates, candies, cookies or sweet cookies?"

(ii.4) Regular replacement of meals with snacks (no or yes), defined when the participant reported replacing meals with snacks five or more days a week [35]. This was measured by the question: "On how many days of the week do you replace your lunch or dinner with sandwiches, snacks or pizzas?"

(ii.5) Regular consumption of soft drinks and/or artificial juice (no or yes), which corresponds to the intake of soft drinks or artificial juices on five or more days per week [35]. Obtained from the question: "On how many days a week do you usually drink soda (or artificial juice)?"

(ii.6) Regular consumption of alcoholic beverages (no or yes), defined as the consumption of at least one dose of alcoholic beverage once or more per month [36]. Variable obtained from the questions: "How often do you usually consume an alcoholic beverage? (1-I never drink; 2-Less than once a month and 3-Once or more a month) ".

(ii.7) Abusive alcohol consumption (no or yes), defined as the ingestion of up to four doses on a single occasion in the last 30 days [37]. This variable was obtained from the question: "In the past 30 days, did you consume 4 or more doses of alcoholic drink on a single occasion?".

(ii.8) Smoking, categorized as non-smoker, ex-smoker and current smoker [31]. The questions used to construct this variable were: "Do you currently smoke any tobacco products? (1-Yes, daily; 2-Yes, less than daily and 3-I do not currently smoke) "; "And in the past, did you smoke any tobacco products? (1-Yes and 2-No) "- for those who answered no in the previous item.

(ii.9) Physical inactivity (no or yes). For this variable, the answers to questions related to physical activity in the last three months, frequency and duration of activity in the domains: Leisure physical activity, commuting physical activity and physical activity at work were taken into account. Physical activity scores were built in each of these domains 
by multiplying the weekly frequency by the time dedicated to activity performed on each day. The model questionnaire of the Surveillance System for Risk and Protective Factors for Chronic Diseases by Telephone Survey (Vigitel) [38] was used, which assesses the practice of physical activity in these three domains, using questions already addressed in international questionnaires used in the area such as the International Physical Activity Questionnaire. Women who stated practicing 150 min per week were considered physically active during leisure considering the sum of minutes of the three domains mentioned [39].

(iii) Multimorbidity

Defined as the presence of two or more chronic conditions, categorized as no or yes [9]. The following NCDs were considered for the computation of the variable: systemic arterial hypertension, diabetes mellitus, hypercholesterolemia, cardiovascular disease, stroke, asthma, arthritis/rheumatism, chronic back pain, work-related musculoskeletal disorder (WMSD), depression, mental disorder (schizophrenia, bipolar disorder, psychosis, obsessive compulsive disorder (OCD)), lung diseases (chronic obstructive pulmonary disease (COPD), pulmonary emphysema, chronic bronchitis), cancer, and chronic kidney failure. The question used for each NCD was: "Has any doctor ever given you a diagnosis of ?".

\subsection{Statistical Analysis}

The data were analyzed using the STATA software (StataCorp LLC, version 16.0, College Station, TX, USA). Initially, a descriptive analysis of the variables assessed was performed. The characteristics of the sample were described as absolute (n) and relative (\%) frequencies. Then, bivariate and multiple Poisson analyses were performed to investigate the magnitude of the association between the independent variables and the dependent variable [40]. Poisson's bivariate analysis explored the association between each independent variable and the dependent variable; the results of this analysis were presented as the Crude Prevalence Ratio (PR) and respective 95\% CI. Variables with $p<0.20$ in this analysis were inserted in a Poisson multiple regression model to adjust for potential confounding variables. The final model was adjusted by age group, schooling, race/color, marital status, state of residence, smoking, alcohol abuse, recommended consumption of fruits and vegetables, regular consumption of soda and/or artificial juice, regular consumption of sweets, physical inactivity and multimorbidity. The results of this analysis were presented as an Adjusted Prevalence Ratio (aPR) and 95\% CI. In addition to the general model, multiple regression models were performed to analyze the contribution of each NCD to the NSAH. The statistical significance of the Poisson models was verified by Wald's statistics. Variables with $p<0.05$ were considered statistically significant.

Poisson regression is generally used in epidemiology to analyze longitudinal studies where the response is the number of episodes of an event that occurred in each period. The model equation is:

$$
\log \left(\frac{n}{t}\right)=\beta 0+\beta 1 X 1+\cdots+B k X k
$$

where $n$ is the number of events for a given individual, $t$ the study period and $X k$ the covariates. The parameters $(\beta \mathrm{i})$ of the model are log of relative risks or prevalence ratio.

\subsection{Ethical Aspects}

The PNS was approved by the National Research Ethics Commission of the National Health Council, protocol 328.159/2013. Written consent was obtained from all participants.

\section{Results}

\subsection{Sample Characteristics}

A total of 4233 women living in the Midwest region of Brazil participating in the PNS 2013 were included in the study, 1385 in the state of Goiás, 1067 in the Federal District, 986 in Mato Grosso do Sul and 795 in Mato Grosso.

Table 1 shows the descriptive analysis of the sample. Regarding the age group, $48.5 \%$ of the population was between 18 and 39 years old; $35.2 \%$ of the women had low schooling 
(illiterate/complete elementary school); 51.5\% self-declare themselves with brown skin; $59.7 \%$ had a spouse and $92.0 \%$ live in an urban area. Regarding lifestyle, a prevalence of recommended consumption of fruits and vegetables of $57.6 \%$ was identified; consumption of meat and/or chicken with excess fat of $37.0 \%$; regular consumption of sweets of $21.3 \%$; regular consumption of soft drinks and/or artificial juice of $23.5 \%$. Furthermore, $7.3 \%$ of the women reported regularly replacing meals with snacks. Regular consumption and alcohol abuse was found in $28.5 \%$ and $9.0 \%$ of women, respectively. The prevalence of current smoking was $10.3 \%$ and the prevalence of physical inactivity was $53.7 \%$. Finally, there was a prevalence of multimorbidity of $28.5 \%$ in the sample.

Table 1. Sociodemographic characteristics, lifestyle and multimorbidities in women. Midwest Region, Brazil, National Health Survey, 2013.

\begin{tabular}{|c|c|c|c|}
\hline Variables & Total * $(n=4.233)$ & $\%$ & $95 \% \mathrm{CI}$ \\
\hline \multicolumn{4}{|l|}{ Age group (years) } \\
\hline $18-39$ & 1.013 & 48.5 & $45.2-52.0$ \\
\hline $40-59$ & 1.478 & 35.0 & $33.1-36.9$ \\
\hline$\geq 60$ & 743 & 16.5 & $15.0-18.1$ \\
\hline \multicolumn{4}{|l|}{ Schooling } \\
\hline No schooling/incomplete elementary school & 1.452 & 34.3 & $32.2-36.4$ \\
\hline Complete elementary school/incomplete high school & 671 & 15.8 & $14.3-17.4$ \\
\hline Complete high school/incomplete higher education & 1.458 & 34.4 & $32.4-36.6$ \\
\hline Complete higher education or higher & 654 & 15.4 & $13.9-17.1$ \\
\hline \multicolumn{4}{|l|}{ Race/skin color } \\
\hline White & 1.713 & 39.8 & $37.5-42.2$ \\
\hline Black & 331 & 7.2 & $6.3-8.2$ \\
\hline Brown & 2.117 & 51.4 & $49.2-53.7$ \\
\hline Other & 71 & 1.5 & $1.1-2.1$ \\
\hline \multicolumn{4}{|l|}{ Marital status } \\
\hline With spouse & 2.312 & 59.7 & $57.9-61.6$ \\
\hline Without spouse & 1.921 & 40.3 & $38.4-42.1$ \\
\hline \multicolumn{4}{|l|}{ Zone of residence } \\
\hline Rural & 512 & 8.1 & $7.2-9.1$ \\
\hline Urban & 3.721 & 91.9 & $90.9-92.8$ \\
\hline \multicolumn{4}{|l|}{ Recommended consumption of vegetables and fruits } \\
\hline No & 1.750 & 42.4 & $40.2-44.7$ \\
\hline Yes & 2.483 & 57.6 & $55.3-59.8$ \\
\hline \multicolumn{4}{|l|}{ Consumption of meat and/or chicken with excess fat } \\
\hline No & 2.702 & 63.0 & $60.9-65.1$ \\
\hline Yes & 1.531 & 37.0 & $34.9-39.1$ \\
\hline \multicolumn{4}{|l|}{ Regular consumption of sweets } \\
\hline No & 3.343 & 78.5 & $76.8-80.1$ \\
\hline Yes & 890 & 21.5 & $19.9-23.2$ \\
\hline \multicolumn{4}{|l|}{ Regular replacement of meals with snacks } \\
\hline No & 3.913 & 92.7 & $91.5-93.7$ \\
\hline Yes & 320 & 7.3 & $6.3-8.5$ \\
\hline \multicolumn{4}{|l|}{ Regular consumption of soda and/or artificial juice } \\
\hline No & 3.256 & 76.5 & $74.7-78.2$ \\
\hline Yes & 977 & 23.5 & $21.8-25.3$ \\
\hline \multicolumn{4}{|l|}{ Regular consumption of alcoholic beverages } \\
\hline No & 3.004 & 71.5 & $69.7-73.2$ \\
\hline Yes & 1.228 & 28.5 & $26.8-30.3$ \\
\hline \multicolumn{4}{|l|}{ Abusive consumption of alcoholic beverages } \\
\hline No & 2.870 & 91.0 & 89.7-91.1 \\
\hline Yes & 363 & 9.0 & $7.9-10.3$ \\
\hline \multicolumn{4}{|l|}{ Smoking } \\
\hline Never & 3.221 & 76.3 & $74.4-78.1$ \\
\hline Ex smoker & 577 & 13.3 & $12.0-14.7$ \\
\hline Current smoker & 435 & 10.4 & $9.3-11.7$ \\
\hline
\end{tabular}


Table 1. Cont.

\begin{tabular}{cccc}
\hline Variables & Total * $(\boldsymbol{n}=\mathbf{4 . 2 3 3})$ & $\mathbf{\%}$ & $\mathbf{9 5 \%} \mathbf{C I}$ \\
\hline Physical inactivity & & & \\
No & 1.986 & 46.6 & $44.6-48.7$ \\
Yes & 2.247 & 53.4 & $51.3-55.4$ \\
Nutritional status & & & \\
Low weight & 100 & 2.5 & $1.9-3.2$ \\
Eutrophic & 1.564 & 40.1 & $38.3-41.9$ \\
Overweight & 1.365 & 32.3 & $30.5-34.2$ \\
Obesity & 1.047 & 25.1 & $23.5-26.9$ \\
Multimorbidity & & & \\
No & 3.039 & 78.5 & $69.7-73.3$ \\
Yes & 1.194 & 28.5 & $26.7-30.4$ \\
\hline
\end{tabular}

${ }^{*}$ Number of valid responses; $95 \% \mathrm{CI}=95 \%$ confidence interval.

\subsection{Health Self-Assessment}

Of the total number of women, $13.4 \%(95 \% \mathrm{CI}=12.1-14.9 \%), 54.9 \%(95 \% \mathrm{CI}=$ $51.9-55.9 \%), 26.8 \%(95 \% \mathrm{CI}=25.0-28.7 \%), 4.9 \%(95 \% \mathrm{CI}=4.1-5.8 \%)$ and $0.9 \%(95 \% \mathrm{CI}=$ 0.6-1.4\%) rated their health as very good, good, fair, poor and very poor, respectively. Thus, considering the definition adopted in this study, the prevalence of NSAH (poor/very poor) in the sample was $6.0 \%(95 \% \mathrm{CI}=5.1-7.0 \%)$.

\subsection{Factors Associated with Negative Health Self-Assessment}

Poisson's bivariate analysis revealed an association between NSAH and the following variables: age group, schooling, race/skin color, recommended consumption of fruits and vegetables, regular consumption of soda, regular consumption of sweets, physical inactivity and multimorbidity, as shown in Table 2.

Table 2. Bivariate analysis of factors associated with negative health self-assessment in women. Midwest Region, Brazil, National Health Survey, 2013.

\begin{tabular}{|c|c|c|c|c|c|c|}
\hline \multirow{2}{*}{ Variables } & \multirow{2}{*}{$\begin{array}{c}\text { Total } \\
(n=4.233)\end{array}$} & \multicolumn{2}{|r|}{ NSAH } & \multirow{2}{*}{ PR } & \multirow{2}{*}{$95 \%$ CI } & \multirow{2}{*}{$p^{*}$} \\
\hline & & $n$ & $\%(95 \% \mathrm{CI})$ & & & \\
\hline \multicolumn{7}{|l|}{ Age group (years) } \\
\hline $18-39$ & 2.012 & 45 & $2.2(1.6-3.1)$ & 1.00 & & \\
\hline $40-59$ & 1.478 & 108 & $7.8(6.1-9.9)$ & 3.56 & $2.32-5.46$ & $<0.001$ \\
\hline$\geq 60$ & 743 & 95 & $13.4(10.4-17.1)$ & 6.13 & $4.06-9.27$ & $<0.001$ \\
\hline \multicolumn{7}{|l|}{ Schooling } \\
\hline $\begin{array}{l}\text { No schooling/incomplete } \\
\text { elementary school }\end{array}$ & 1.489 & 173 & $12.4(10.4-14.8)$ & 7.78 & $3.80-15.90$ & $<0.001$ \\
\hline $\begin{array}{l}\text { Complete elementary } \\
\text { school/incomplete high } \\
\text { school }\end{array}$ & 651 & 24 & $3.7(2.2-6.2)$ & 2.32 & $0.96-5.62$ & 0.062 \\
\hline $\begin{array}{l}\text { Complete high } \\
\text { school/incomplete higher } \\
\text { education }\end{array}$ & 1.405 & 39 & $2.6(1.8-3.9)$ & 1.65 & $0.74-3.69$ & 0.218 \\
\hline $\begin{array}{l}\text { Complete higher } \\
\text { education or higher }\end{array}$ & 688 & 12 & $1.6(0.8-3.2)$ & 1.00 & & \\
\hline \multicolumn{7}{|l|}{ Race/skin color } \\
\hline White & 1.713 & 87 & $5.4(4.1-7.0)$ & 1.00 & & \\
\hline Black & 331 & 29 & $9.2(6.1-13.8)$ & 1.71 & $1.03-2.83$ & 0.037 \\
\hline Brown & 2.117 & 125 & $5.8(4.6-7.3)$ & 1.07 & $0.75-1.54$ & 0.705 \\
\hline Other & 71 & 7 & $14.0(5.6-30.9)$ & 2.59 & $1.04-6.48$ & 0.042 \\
\hline \multicolumn{7}{|l|}{ Marital status } \\
\hline With spouse & 2.312 & 115 & $5.4(4.3-6.7)$ & 0.77 & $0.58-1.04$ & 0.090 \\
\hline Without spouse & 1.921 & 133 & $6.9(5.6-8.5)$ & 1.00 & & \\
\hline
\end{tabular}


Table 2. Cont.

\begin{tabular}{|c|c|c|c|c|c|c|}
\hline \multirow{2}{*}{ Variables } & \multirow{2}{*}{$\begin{array}{c}\text { Total } \\
(n=4.233)\end{array}$} & \multicolumn{2}{|r|}{ NSAH } & \multirow{2}{*}{ PR } & \multirow{2}{*}{$95 \% \mathrm{CI}$} & \multirow{2}{*}{$p^{*}$} \\
\hline & & $n$ & $\%(95 \% \mathrm{CI})$ & & & \\
\hline \multicolumn{7}{|l|}{ Zone of residence } \\
\hline Rural & 512 & 31 & $6.6(4.2-10.1)$ & 1.10 & $0.69-1.77$ & 0.665 \\
\hline Urban & 3.721 & 217 & $5.9(5.1-7.0)$ & 1.00 & & \\
\hline \multicolumn{7}{|l|}{ State of residence } \\
\hline Federal District & 1.067 & 66 & $5.8(4.5-7.5)$ & 1.0 & & \\
\hline Goiás & 1.385 & 78 & $5.9(4.5-7.7)$ & 1.02 & $0.70-1.48$ & 0.938 \\
\hline Mato Grosso & 795 & 48 & $6.4(4.6-9.0)$ & 1.11 & $0.73-1.70$ & 0.631 \\
\hline Mato Grosso do Sul & 986 & 56 & $6.0(4.4-8.0)$ & 1.03 & $0.70-1.54$ & 0.887 \\
\hline \multicolumn{7}{|c|}{$\begin{array}{l}\text { consumption of vegetables } \\
\text { and fruits }\end{array}$} \\
\hline No & 1.750 & 131 & $8.0(6.5-9.8)$ & 1.00 & & \\
\hline Yes & 2.483 & 117 & $4.5(3.6-5.7)$ & 0.56 & $0.41-0.77$ & $<0.001$ \\
\hline \multicolumn{7}{|l|}{$\begin{array}{l}\text { Consumption of meat } \\
\text { and/or chicken with } \\
\text { excess fat }\end{array}$} \\
\hline No & 2.702 & 167 & $6.0(5.0-7.3)$ & 1.00 & & \\
\hline Yes & 1.531 & 81 & $6.0(4.6-7.7)$ & 0.99 & $0.72-1.36$ & 0.951 \\
\hline \multicolumn{7}{|l|}{$\begin{array}{l}\text { Regular consumption of } \\
\text { sweets }\end{array}$} \\
\hline No & 3.343 & 221 & $6.6(5.7-7.8)$ & 1.00 & & \\
\hline Yes & 890 & 27 & $3.7(2.3-5.9)$ & 0.56 & $0.34-0.91$ & 0.019 \\
\hline \multicolumn{7}{|l|}{$\begin{array}{l}\text { Regular replacement of } \\
\text { meals with snacks }\end{array}$} \\
\hline No & 3.913 & 234 & $6.1(5.2-7.1)$ & 1.00 & & \\
\hline Yes & 320 & 14 & $5.3(3.0-9.2)$ & 0.87 & $0.48-1.57$ & 0.641 \\
\hline \multicolumn{7}{|c|}{$\begin{array}{l}\text { Regular consumption of } \\
\text { soda and/or artificial juice }\end{array}$} \\
\hline No & 3.256 & 207 & $6.6(5.6-7.8)$ & 1.00 & & \\
\hline Yes & 977 & 41 & $3.9(2.7-5.7)$ & 0.59 & $0.39-0.89$ & 0.013 \\
\hline \multicolumn{7}{|l|}{$\begin{array}{l}\text { Regular consumption of } \\
\text { alcoholic beverages }\end{array}$} \\
\hline No & 3.005 & 214 & $7.2(6.1-8.4)$ & 1.00 & & \\
\hline Yes & 1.228 & 34 & $3.1(2.0-4.6)$ & 0.43 & $0.27-0.66$ & $<0.001$ \\
\hline \multicolumn{7}{|l|}{$\begin{array}{l}\text { Abusive consumption of } \\
\text { alcoholic beverages }\end{array}$} \\
\hline No & 3.870 & 234 & $6.2(5.3-7.2)$ & 1.00 & & \\
\hline Yes & 363 & 14 & $4.1(2.1-7.6)$ & 0.65 & $0.34-1.27$ & 0.211 \\
\hline \multicolumn{7}{|l|}{ Smoking } \\
\hline Never & 3.221 & 148 & $4.6(3.7-5.7)$ & 1.00 & & \\
\hline Ex smoker & 577 & 67 & $12.5(9.4-16.5)$ & 2.72 & $1.91-3.87$ & $<0.001$ \\
\hline Current smoker & 435 & 33 & $7.8(5.2-11.6)$ & 1.70 & $1.08-2.68$ & 0.022 \\
\hline \multicolumn{7}{|l|}{ Physical inactivity } \\
\hline No & 1.986 & 80 & $4.2(3.2-5.4)$ & 1.00 & & \\
\hline Yes & 2.247 & 168 & $7.6(6.2-9.2)$ & 1.81 & $1.30-2.51$ & $<0.001$ \\
\hline \multicolumn{7}{|l|}{ Multimorbidity } \\
\hline No & 3.039 & 67 & $2.6(1.9-3.5)$ & 1.00 & & \\
\hline Yes & 1.194 & 181 & $14.6(12.3-17.2)$ & 5.69 & $4.04-8.02$ & $<0.001$ \\
\hline
\end{tabular}

NSAH = Negative Self-Assessment of Health; PR = Prevalence Ratio; $95 \%$ CI = 95\% Confidence Interval; * Wald statistic.

Table 3 shows the final Poisson model of the factors associated with NSAH. Variables with a $p$-value $<0.20$ were included in the final model in the bivariate analysis. The model showed that the prevalence of NSAH was 2.43 -fold higher (aPR: $2.43 ; 95 \% \mathrm{CI}=$ 1.07-5.52) in women aged 40-59 years and 2.52 (aPR: 2.52; 95\% CI $=1.02-6.23$ ) fold higher in those aged 60 years or over, when compared to younger women. The prevalence was also 4.85-fold higher (aPR: 4.85; 95\% CI = 2.27-10.37) in women with the lowest level 
of schooling (illiterate/incomplete elementary school) when compared to those with the highest level (higher education). This prevalence was 1.55 -fold higher (aPR: 1.55; 95\% CI = 1.11-2.15) in women who presented inactivity when compared to active women. Finally, the prevalence of NSAH was 6.93-fold (aPR: 6.93; 95\% CI = 3.47-13.85) higher in women with multimorbidity when compared to those without this characteristic. These results indicate that multimorbidity is the condition that most impacts on women's NSAH. In addition, they suggest an increase in negative self-assessment of health with increasing age and association with low schooling and physical inactivity.

Table 3. Multiple regression analysis of factors associated with negative health self-assessment in women. Midwest Region, Brazil, National Health Survey, 2013.

\begin{tabular}{|c|c|c|c|c|}
\hline Variables & aPR & $95 \% \mathrm{CI}$ & SE & $p^{*}$ \\
\hline \multicolumn{5}{|l|}{ Age group (years) } \\
\hline $18-39$ & 1.00 & & & \\
\hline $40-59$ & 2.43 & $1.07-5.52$ & 1.01 & 0.034 \\
\hline$\geq 60$ & 2.52 & $1.02-6.23$ & 1.16 & 0.045 \\
\hline \multicolumn{5}{|l|}{ Schooling } \\
\hline No schooling/incomplete elementary school & 1.00 & & & \\
\hline Complete elementary school/incomplete high school & 1.95 & $0.87-4.37$ & 0.80 & 0.102 \\
\hline Complete high school/incomplete higher education & 2.31 & $0.95-5.60$ & 1.04 & 0.065 \\
\hline Complete higher education or higher & 4.85 & $2.27-10.37$ & 1.88 & $<0.001$ \\
\hline \multicolumn{5}{|l|}{ Race/skin color } \\
\hline White & 1.00 & & & \\
\hline Black & 1.59 & $0.96-2.63$ & 0.41 & 0.068 \\
\hline Brown & 1.02 & $0.71-1.47$ & 0.19 & 0.893 \\
\hline Other & 2.01 & $0.79-5.11$ & 0.95 & 0.141 \\
\hline \multicolumn{5}{|l|}{ Marital status } \\
\hline With spouse & 1.00 & & & \\
\hline Without spouse & 0.89 & $0.65-1.21$ & 0.14 & 0.456 \\
\hline \multicolumn{5}{|l|}{ State of residence } \\
\hline Federal District & 1.00 & & & \\
\hline Goiás & 0.71 & $0.49-1.03$ & 0.13 & 0.071 \\
\hline Mato Grosso & 0.79 & $0.52-1.20$ & 0.17 & 0.275 \\
\hline Mato Grosso do Sul & 0.74 & $0.50-1.09$ & 0.15 & 0.126 \\
\hline \multicolumn{5}{|l|}{ Recommended consumption of vegetables and fruits } \\
\hline No & 1.00 & & & \\
\hline Yes & 0.79 & $0.40-1.56$ & 0.27 & 0.496 \\
\hline \multicolumn{5}{|l|}{ Regular consumption of sweets } \\
\hline No & 1.00 & & & \\
\hline Yes & 0.75 & $0.45-1.25$ & 0.19 & 0.270 \\
\hline \multicolumn{5}{|l|}{ Regular consumption of soda and/or artificial juice } \\
\hline No & 1.00 & & & \\
\hline Yes & 0.79 & $0.52-1.20$ & 0.17 & 0.266 \\
\hline \multicolumn{5}{|l|}{ Abusive consumption of alcoholic beverages } \\
\hline No & 1.00 & & & \\
\hline Yes & 1.01 & $0.55-1.88$ & 0.32 & 0.950 \\
\hline \multicolumn{5}{|l|}{ Smoking } \\
\hline Never & 1.00 & & & \\
\hline Ex smoker & 1.30 & $0.90-1.89$ & 0.25 & 0.160 \\
\hline Current smoker & 1.22 & $0.79-1.88$ & 0.27 & 0.370 \\
\hline \multicolumn{5}{|l|}{ Physical inactivity } \\
\hline No & 1.00 & & & \\
\hline Yes & 1.55 & $1.11-2.15$ & 0.26 & 0.009 \\
\hline \multicolumn{5}{|l|}{ Multimorbidity } \\
\hline No & 1.00 & & & \\
\hline Yes & 6.93 & $3.47-13.85$ & 2.44 & $<0.001$ \\
\hline
\end{tabular}

aPR = Adjusted Prevalence Ratio; 95\% CI = 95\%Confidence Interval; SE = Standard Error; ${ }^{*}$ Wald Statistic Note: Poisson multiple regression model adjusted by age group, education, race/skin color, marital status, state of residence, recommended consumption of fruits and/or vegetables, regular consumption of sweets, regular consumption of soft drinks, abusive consumption of alcoholic beverages, smoking, physical inactivity and multimorbidity. 
Figure 1 shows the aPR and 95\% CI of the multiple regression models that assessed the magnitude of the association between each chronic condition and NSAH in women. There was a significant association between NSAH and chronic back pain, mental disorders (bipolarity, schizophrenia and obsessive compulsive disorder), depression, cardiovascular disease, cancer, stroke, arthritis, hypercholesterolemia, systemic arterial hypertension and diabetes mellitus.

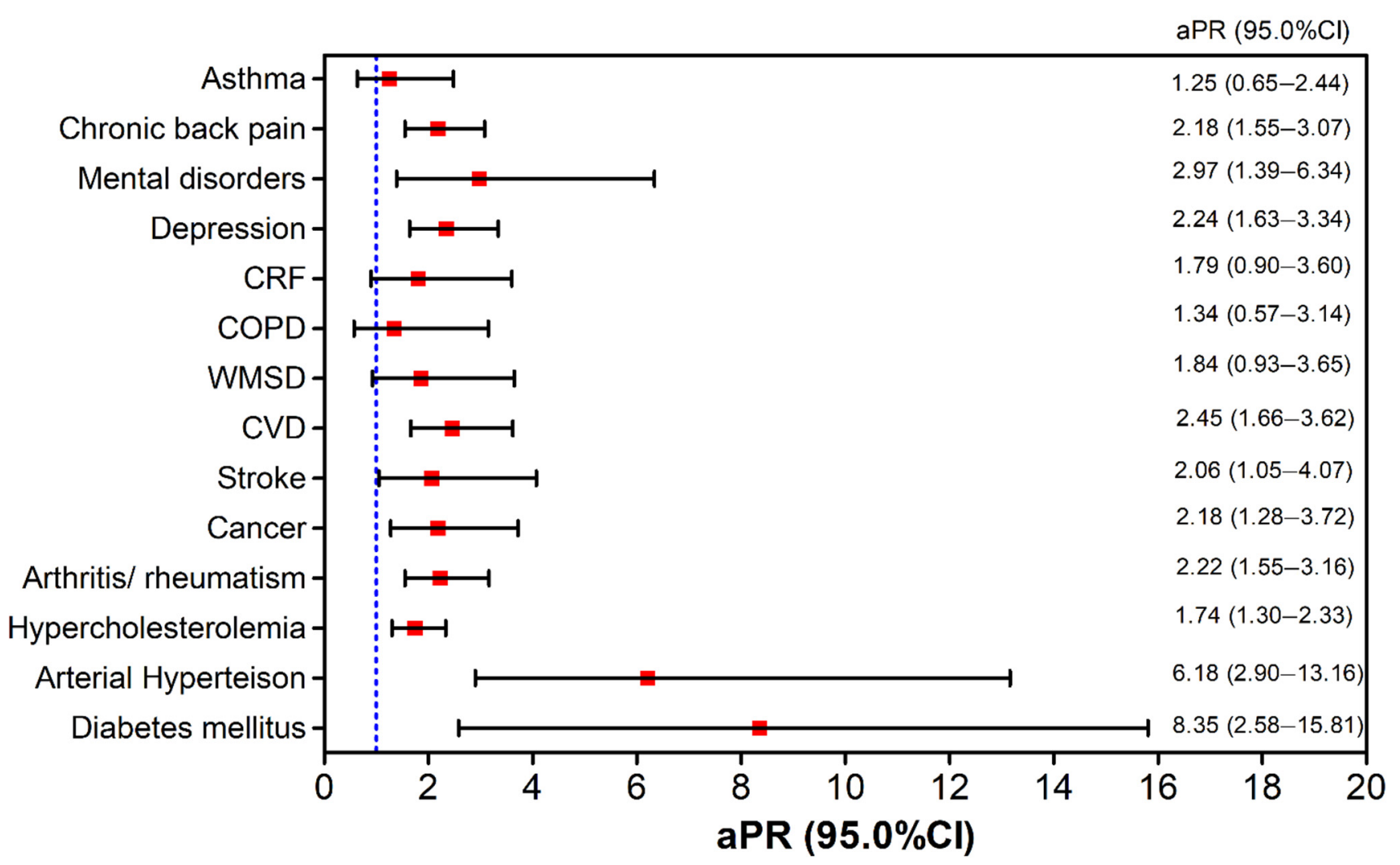

Figure 1. Analysis of the association between negative health self-assessment and chronic conditions in women in the Midwest region, Brazil, National Health Survey, 2013. aPR = Adjusted Prevalence Ratio; 95\% CI = 95\% Confidence Interval; WMSD = Work-related Musculoskeletal Disease; $\mathrm{CRF}=$ chronic renal failure; $\mathrm{COPD}=$ Chronic Obstructive Pulmonary Disease $; \mathrm{CVD}=$ cardiovascular diseases.

\section{Discussion}

The results from this study revealed a low prevalence of NSAH in women in the Midwest region. Additionally, multiple regression analysis showed a positive gradient of NSAH with increasing age group; in addition to the association with low level of education and physical inactivity. Finally, a strong association between multimorbidity and NSAH was observed in the sample under study.

The prevalence of NSAH found in this study was $6.0 \%$ (95\% CI: 5.1-7.0), similar to that found in the female population of Brazil in 2013 (6.8\%) [18]. On the other hand, the estimated prevalence was statistically lower than that found in the female population of the country in 2008 (44.4\%) [41] and 2003 (11.5\%) [42]. Szwarcwald et al. [19] point out that this decrease is paradoxical, since the aging of the population and the increase in the magnitude of NCDs tend to increase the prevalence of NSAH, not decrease. However, increased access to health services, higher family income and education, in addition to the greater participation of women in the labor market over the years, may have contributed to the reduction in the prevalence of NSAH in recent years in Brazil [18]. The low prevalence found can also be attributed to the scope of the National Policy for Integral Attention to Women's Health (PNAISM), which in Brazil has solid bases and actions in the field of 
well-established primary care, focusing on health promotion and disease prevention, such as NCDs [43].

This phenomenon demands a reflection on the dimensions involved in the NSAH construct. The association between NSAH and multimorbidity, found in this study, indicates that women possibly took into account the biological dimension of health in their perception. However, considering that this health indicator encompasses the physical, emotional components of well-being and satisfaction with one's own life, it is hypothesized that: 1 . in a gender perspective, it is possible that the low prevalence of NSAH may be the result of greater autonomy gained in different dimensions of life, active participation in different work spaces and conquest, although not entirely of equality between men and women; 2. that the health view is still restricted to biological aspects in common sense, disregarding or attributing less value to other factors contained in the holistic definition of health.

In the present study, a positive gradient was observed between the prevalence of NSAH and an increase in age group. In fact, studies have shown an increase in NSAH with increasing age in Brazilian women [18,19,44] and from other countries [23,45]. With increasing age, people are more susceptible to NCDs that compromise functionality and increase dependence, which can lead to an NSAH $[17,18,23]$. Studies on NSAH in the elderly show that the prevalence is higher than in other age groups, and the outcome of the increased prevalence of NCDs and unhealthy life habits throughout life [46,47]. Compared to men, this is an important result, because in old age, women still tend to undertake other roles in the family, such as caregivers of children, grandchildren, and elderly spouses, leading to overload, worse quality of life [48,49], and consequently NSAH.

This study revealed an association between low level of education and NSAH in the study sample, indicating inequities of this indicator regarding the level of education. Similarly, other studies conducted with women have shown an association between education level and NSAH $[18,45,50]$. A survey that analyzed associations between educational level and NSAH among adults in Brazil from 1998 to 2013 showed a clear association between low schooling and NSAH, even with the improvement of schooling in the general population in recent years [50]. Evidence shows that education is a strong social determinant of health in Brazil, and individuals with lower education have lower income, higher prevalence of morbidity and lower access to health services, which contributes to a greater magnitude of NSAH at lower educational levels $[18,27,50]$.

Social determinants and conditions, such as schooling, stand out in the analysis of the data of the present study, in the context of public health. These findings are not limited to Brazil, although the specificities of our sociocultural organization are important to analyze the findings and propose improvement strategies. For example, a study published in the USA identified higher NSAH among older and black women with low schooling and low income [51].

Physical inactivity was significantly associated with NSAH in the study sample, corroborating other studies conducted in women $[16,17,23,52,53]$. It is estimated that the prevalence of physical inactivity affects almost half of the Brazilian population (46.0\%), with a higher frequency in women than men (51.5\% versus $29.8 \%$ ) [39]. The present study also showed a high prevalence of physical inactivity in women (53.3\%). Studies indicate that insufficient physical inactivity is associated with several negative health effects, such as insulin resistance and type 2 diabetes; depressive symptoms, hypertension, obesity and other diseases that in turn influence NSAH [54]. Moreover, from a broader perspective of health, the relationship between regular physical activity and self-perception of health may be associated with better quality of life, general health and biopsychosocial well-being of women, self-care, independence, stress reduction and the risk of morbidity by various causes, including NCDs $[55,56]$, which contributes to the positive effect of this variable on positive self-assessment of health.

Finally, the present study showed a strong association between multimorbidity and NSAH, corroborating previous findings [16]. The prevalence of NSAH increased 6.93-fold 
in women with multimorbidity when compared to those without this characteristic. The strength of the associations between multimorbidity and NSAH differs between studies. A cross-sectional study conducted in Canada with women showed that the presence of two or more chronic health conditions increases the likelihood of NSAH by 9.73 fold [16]. Research conducted in England found that the likelihood of moderate or poor self-assessment increases 1.5 to 2.2 fold in the presence of two and three or more chronic conditions, respectively [13]. In Brazil, a study conducted in women using multimorbidity as a predictor of NSAH found that NSAH increased the probability of having two or more chronic conditions by 5.1-fold [57]. Studies that include mental disorders, such as depression, in the multimorbidity equation, display stronger likelihood of association, since these disorders are considered a major risk factor for NSAH [15].

The present study also showed that among the 13 diseases or groups of diseases investigated to estimate the prevalence of multimorbidity, 10 were statistically associated with NSAH after control of the other covariates. These diseases/health conditions included chronic back pain, systemic arterial hypertension, mental disorders, depression, cardiovascular diseases, stroke, cancer, hypercholesterolemia, and diabetes mellitus. However, the greatest strength of association was, in this order: diabetes mellitus, hypertension, mental disorders, depression and chronic back pain. All conditions require several procedures for their control, including changes in life habits, risk monitoring and drug treatment, which can imply complexity to the therapeutic regimen and influence the perception of one's own health. Additionally, considering that self-perceived health is a multidetermined indicator, diseases such as diabetes and back problems bring long-term complications that may be tied to a dimension of physical health. Mental disorders and depression, in turn, may reflect women's emotional health conditions $[58,59]$.

\section{Limitations}

This study has some limitations. First, the cross-sectional nature does not allow the establishment of cause-and-effect relationships between the dependent variable and the independent variables analyzed. Second, the data related to lifestyle were self-reported, susceptible to memory and response bias, and their magnitudes may be underestimated. To reduce memory and response bias, two strategies were used. To reduce memory bias, the validated questions used the shortest possible time periods (one week, one month or three months) or the habit of that behavior. To minimize response bias, the participants were interviewed by a researcher in a place of residence, without the presence of other family members. Third, NCDs measured to assess multimorbidity were also self-reported, and laboratory and/or clinical methods for diagnosis were not used and may also be underestimated. Fourth, the sample did not have the power to perform sensitivity analyses of the factors associated with NSAH, according to age groups, race/skin color and schooling, which are essential to assess differences in predictors according to sociodemographic characteristics. The small number of cases of the outcome $(n=248)$ did not allow the stratification of the sensitivity analyses, since it increased the $95 \%$ confidence intervals of the estimates and reduced the power of discrimination of the variables. Despite the limitations, this is one of the few studies that evaluated the magnitude of the factors associated with NSAH in a sample of women from Brazil, which may contribute to the formulation and implementation of public policies to improve the quality of life of this population.

\section{Conclusions}

In conclusion, the prevalence of NSAH found in this study was low $(6.0 \%)$. Furthermore, NSAH was statistically associated with advancing age, low level of education, physical inactivity and multimorbidity. The findings of this study may contribute to the strengthening of public health promotion policies focused on primary health care aimed at improving the perception of women's health through action on its determinants. This includes strengthening coping strategies for risk factors for NCDs, especially physical inactivity; actions to reduce NCDs, aiming at reducing the prevalence of multimorbidity; in- 
terventions aimed at more vulnerable groups, especially older women with low education. In Brazil, the Plan to Combat Chronic Noncommunicable Diseases 2021-2030 [60] is an example of a political initiative to face NCDs, which will impact the negative perception of health. Future studies should investigate NSAH as a predictor of morbidity and mortality in women; perform stratified analyses of the associated factors by age groups and analyze other variables associated with NSAH in this population.

Author Contributions: Conceptualization, T.A.d.P.S., R.A.G., V.P., N.D.A.A., I.S.L.d.S., S.D.R., C.I.d.S.C. and C.F.W.R.; methodology, R.A.G.; validation, T.A.d.P.S. and R.A.G.; formal analysis, R.A.G.; investigation, T.A.d.P.S., R.A.G., V.P., N.D.A.A., I.S.L.d.S., S.D.R., C.I.d.S.C. and C.F.W.R.; data curation, R.A.G.; writing-original draft preparation, T.A.d.P.S., R.A.G., V.P., N.D.A.A., I.S.L.d.S., S.D.R., C.I.d.S.C. and C.F.W.R.; writing-review and editing, T.A.d.P.S., R.A.G., V.P., N.D.A.A., I.S.L.d.S., S.D.R., C.I.d.S.C. and C.F.W.R.; visualization, T.A.d.P.S., R.A.G., V.P., N.D.A.A., I.S.L.d.S., S.D.R., C.I.d.S.C. and C.F.W.R.; supervision, R.A.G.; project administration, R.A.G. All authors have read and agreed to the published version of the manuscript.

Funding: The survey data used in the study was financed by the Brazilian Ministry of Health (no. 328 159, 26 June 2013).

Institutional Review Board Statement: The study was conducted in accordance with the Declaration of Helsinki, and approved by the Ethics Committee of National Research Ethics Commission of the National Health Council, protocol 328.159/2013, for studies involving humans.

Informed Consent Statement: Written informed consent was obtained from all subjects involved in the study.

Data Availability Statement: Available from: https://www.ibge.gov.br/estatisticas/sociais/justicae-seguranca/29540-2013-pesquisa-nacional-de-saude.html, (accessed on 12 November 2021).

Conflicts of Interest: The authors declare no conflict of interest.

\section{References}

1. World Health Organization. Noncomunicable Diseases Country Profiles 2018; WHO: Geneva, Switzerland, 2018. Available online: https:/ / www.who.int/nmh/publications/ncd-profiles-2018/en/ (accessed on 18 November 2021).

2. Muka, T.; Imo, D.; Jaspers, L.; Colpani, V.; Chaker, L.; van der Lee, S.J.; Mendis, S.; Chowdhury, R.; Bramer, W.; Falla, A.; et al. The global impact of non-communicable diseases on healthcare spending and national income: A systematic review. Eur. J. Epidemiol. 2015, 30, 251-277. [CrossRef] [PubMed]

3. Lozano, R.; Fullman, N.; Mumford, J.E.; Knight, M.; Barthelemy, C.M.; Abbafati, C.; Abbastabar, H.; Abd-Allah, F.; Abdollahi, M.; Abedi, A.; et al. Measuring universal health coverage based on an index of effective coverage of health services in 204 countries and territories, 1990-2019: A systematic analysis for the Global Burden of Disease Study 2019. Lancet 2020, 396, 1250-1284. [CrossRef]

4. World Health Organization. Global Action Plan for the Prevention and Control of Noncommunicable Diseases; WHO: Geneva, Switzerland, 2013. Available online: https:/ / www.who.int/publications/i/item/9789241506236 (accessed on 18 November 2021).

5. Vos, T.; Lim, S.S.; Abbafati, C.; Abbas, K.M.; Abbasi, M.; Abbasifard, M.; Abbasi-Kangevari, M.; Abbastabar, H.; Abd-Allah, F.; Abdelalim, A.; et al. Global burden of 369 diseases and injuries in 204 countries and territories, 1990-2019: A systematic analysis for the Global Burden of Disease Study 2019. Lancet 2020, 396, 10258. [CrossRef]

6. Marinho, F.; de Azeredo Passos, V.M.; Carvalho Malta, D.; Barboza França, E.; Abreu, D.M.X.; Araújo, V.E.M.; Bustamante-Teixeira, M.T.; Camargos, P.A.M.; da Cunha, C.C.; Duncan, B.B.; et al. Burden of disease in Brazil, 1990-2016: A systematic subnational analysis for the Global Burden of Disease Study 2016. Lancet 2018, 392, 760-775. [CrossRef]

7. Marmot, M.; Bell, R. Social determinants and non-communicable diseases: Time for integrated action. BMJ $2019,364,364$. [CrossRef] [PubMed]

8. Malta, D.C.; Bernal, R.T.I.; Nunes, M.L.; Oliveira, M.M.D.; Iser, B.P.M.; Andrade, S.S.C.D.A.; Claro, R.M.; Monteiro, C.A.; Silva, J.B.d., Jr. Prevalência de fatores de risco e proteção para doenças crônicas não transmissíveis em adultos: Estudo transversal, Brasil 2012. Epidemiol. Serviços Saúde 2014, 23, 609-622. [CrossRef]

9. Johnston, M.C.; Crilly, M.; Black, C.; Prescott, G.J.; Mercer, S.W. Defining and measuring multimorbidity: A systematic review of systematic reviews. Eur. J. Public Health 2019, 29, 182-189. [CrossRef]

10. Eyowas, F.A.; Schneider, M.; Yirdaw, B.A.; Getahun, F.A. Multimorbidity of chronic non-communicable diseases and its models of care in low-and middle-income countries: A scoping review protocol. BMJ Open 2019, 9, e033320. [CrossRef]

11. Nguyen, H.; Manolova, G.; Daskalopoulou, C.; Vitoratou, S.; Prince, M.; Prina, A.M. Prevalence of multimorbidity in community settings: A systematic review and meta-analysis of observational studies. J. Comorbidity 2019, 9, 2235042X1987093. [CrossRef] 
12. Sum, G.; Ishida, M.; Koh, G.C.H.; Singh, A.; Oldenburg, B.; Lee, J.T. Implications of multimorbidity on healthcare utilisation and work productivity by socioeconomic groups: Cross-sectional analyses of Australia and Japan. PLoS ONE 2020, 15, e0232281. [CrossRef]

13. Mavaddat, N.; Valderas, J.M.; Van Der Linde, R.; Khaw, K.T.; Kinmonth, A.L. Association of self-rated health with multimorbidity, chronic disease and psychosocial factors in a large middle-aged and older cohort from general practice: A cross-sectional study. BMC Fam. Pract. 2014, 15, 185. [CrossRef] [PubMed]

14. Sheridan, P.E.; Mair, C.A.; Quinõnes, A.R. Associations between prevalent multimorbidity combinations and prospective disability and self-rated health among older adults in Europe. BMC Geriatr. 2019, 19, 198. [CrossRef] [PubMed]

15. Feenstra, M.; Van Munster, B.C.; Vroomen, J.L.M.; De Rooij, S.E.; Smidt, N. Trajectories of self-rated health in an older general population and their determinants: The Lifelines Cohort Study. BMJ Open 2020, 10, e035012. [CrossRef] [PubMed]

16. Cui, Y.; Sweeney, E.; Forbes, C.; DeClercq, V.; Grandy, S.A.; Keats, M.; Parker, L.; Yu, Z.M.; Dummer, T.J. The association between physical activity and self-rated health in Atlantic Canadians. J. Women Aging 2020, 33, 596-610. [CrossRef] [PubMed]

17. Silva, V.H.; Rocha, J.S.B.; Caldeira, A.P. Factors associated with negative self-rated health in menopausal women. Cienc. Saude Coletiva 2018, 23, 1611-1620. [CrossRef]

18. de Sousa, J.L.; Alencar, G.P.; Antunes, J.L.F.; da Silva, Z.P. Markers of inequality in self-rated health in Brazilian adults according to sex. Cadernos Saude Publica 2020, 36. [CrossRef]

19. Szwarcwald, C.L.; Damacena, G.N.; Souza Júnior, P.R.B.D.; Almeida, W.D.S.D.; Lima, L.T.M.D.; Malta, D.C.; Stopa, S.R.; Vieira, M.L.F.P.; Pereira, C.A. Determinantes da autoavaliação de saúde no Brasil e a influência dos comportamentos saudáveis: Resultados da pesquisa nacional de saúde, 2013. Rev. Bras. Epidemiol. 2015, 18, 33-44. [CrossRef]

20. Patrão, A.L.; Almeida, M.d.C.C.; Alvim, S.; Chor, D.; Aquino, E.M.L. Health behavior-related indicator of lifestyle: Application in the ELSA-Brasil study. Glob. Health Promot. 2019, 26, 62-69. [CrossRef]

21. Mussi, R.F.d.F.; Queiroz, B.M.d.; Petróski, E.L. Overweight and associated factors in quilombolas from the middle San Francisco, Bahia, Brazil. Cienc. Saude Coletiva 2018, 23, 1193-1200. [CrossRef]

22. Wang, X.; Zhang, M.; Wang, Z.H.; Zhang, X.; Zhao, Z.P.; Huang, Z.J.; Qi, S.G.; Li, C.; Xu, X.H.; Wang, L.M.; et al. Correlation between hypertension label and self-rated health in adult residents in China. Chin. J. Epidemiol. 2019, 41, 379-384.

23. Mendoza-Romero, D.; Urbina, A.; Cristancho-Montenegro, A.; Rombaldi, A. Impact of smoking and physical inactivity on self-rated health in women in Colombia. Prev. Med. Rep. 2019, 16, 100976. [CrossRef]

24. Theme Filha, M.M.; Souza Junior PR, B.D.; Damacena, G.N.; Szwarcwald, C.L. Prevalence of chronic non-communicable diseases and association with self-rated health: National Health Survey, 2013. Rev. Bras. Epidemiol. 2015, 18 (Suppl. 2), S83-S96. [CrossRef]

25. Boerma, T.; Hosseinpoor, A.R.; Verdes, E.; Chatterji, S. A global assessment of the gender gap in self-reported health with survey data from 59 countries. BMC Public Health 2016, 16, 675. [CrossRef]

26. De Andrade, G.F.; Loch, M.R.; Silva, A.M.R. Changes in health-related behaviors as predictors of changes in health self-perception: Longitudinal study (2011-2015). Cad. Saude Publica 2019, 35, e00151418.

27. Pinillos-Franco, S.; García-Prieto, C. The gender gap in self-rated health and education in Spain. A multilevel analysis. PLoS ONE 2017, 12, e0187823. [CrossRef]

28. Szwarcwald, C.L.; Malta, D.C.; Pereira, C.A.; Vieira, M.L.F.P.; Conde, W.L.; Souza Junior, P.R.B.D.; Damacena, G.N.; Azevedo, L.O.; Azevedo e Silva, G.; Theme Filha, M.M.; et al. Pesquisa Nacional de Saude no Brasil: Concepcao e metodologia de aplicacao. Cienc. Saude Coletiva 2014, 19, 333-342. [CrossRef]

29. Souza-Júnior, P.R.B.D.; Freitas, M.P.S.D.; Antonaci, G.D.A.; Szwarcwald, C.L. Desenho da amostra da Pesquisa Nacional de Saúde 2013. Epidemiol. Serviços Saúde 2015, 24, 207-216. Available online: http:/ / www.iec.pa.gov.br/template_doi_ess.php?doi=10.512 3/S1679-49742015000200003\&scielo=S2237-96222015000200207 (accessed on 18 November 2021). [CrossRef]

30. Medeiros, S.M.; Silva, L.S.R.; Carneiro, J.A.; Ramos, G.C.F.; Barbosa, A.T.F.; Caldeira, A.P. Factors associated with negative self-rated health among non-institutionalized elderly in Montes Claros, Brazil. Cienc. Saude Coletiva 2016, 21, 3377-3386. [CrossRef]

31. Guimarães, R.A.; Morais Neto, O.L.d.; Souza, M.R.d.; Cortez-Escalante, J.J.; Santos, T.A.d.P.; Rosso, C.F.W.; Pacheco, M.M.; Leite Júnior, J.F.; Sobrinho França, G.; Fonseca, L.d.J.; et al. Epidemiology of Self-Reported Diabetes Mellitus in the State of Maranhão, Northeastern Brazil: Results of the National Health Survey, 2013. Int. J. Environ. Res. Public Health 2019, 16, 47. [CrossRef]

32. Ministério do Planejamento Orçamento e Gestão, Instituto Brasileiro de Geografia e Estatística, Diretoria de Pesquisas, Coordenação de População e Indicadores Sociais. Características Etnico-Raciais da População: Um Estudo das Categorias de Classificação de cor ou raça 2008. Rio de Janeiro. 2011. Available online: http://biblioteca.ibge.gov.br/visualizacao/livros/liv49891.pdf (accessed on 25 November 2021).

33. WHO. Diet, Nutrition and the Prevention of Chronic Diseases; World Health Organization Technical Report Series; WHO: Geneva, Switzerland, 2003; Volume 916, pp. 1-149.

34. Claro, R.M.; Santos, M.A.S.; Oliveira, T.P.; Pereira, C.A.; Szwarcwald, C.L.; Malta, D.C. Consumo de alimentos não saudáveis relacionados a doenças crônicas não transmissíveis no Brasil: Pesquisa Nacional de Saúde, 2013. Epidemiol. Serviços Saúde 2015, 24, 257-265. [CrossRef]

35. IBGE. Pesquisa Nacional de Saúde Módulo de Estilo de Vida-Consumo de Alimentos Notas Técnicas. 2014. Available online: http:/ / tabnet.datasus.gov.br/cgi/pns/Notas_Tecnicas_PNS_P_A.pdf (accessed on 18 November 2021).

36. Moura, E.C.; Malta, D.C. Alcoholic beverage consumption among adults: Sociodemographic characteristics and trends. Rev. Bras. Epidemiol. 2011, 14 (Suppl. 1), 61-70. [CrossRef] 
37. Courtney, K.E.; Polich, J. Binge Drinking in Young Adults: Data, Definitions, and Determinants. Psychol. Bull. 2009, 135, 142-156. [CrossRef]

38. Ministério da Saúde. Vigitel Brasil 2018-Vigilância de Fatores de Risco e Proteção para Doenças Crônicas por Inquérito Telefônico 2019; p. 131. Available online: https://portalarquivos2.saude.gov.br/images/pdf/2019/julho/25/vigitel-brasil-2018.pdf (accessed on 10 November 2019).

39. Mielke, G.I.; Hallal, P.C.; Rodrigues, G.B.A.; Szwarcwald, C.L.; Santos, F.V.; Malta, D.C. Prática de atividade física e hábito de assistir à televisão entre adultos no Brasil: Pesquisa Nacional de Saúde 2013. Epidemiol. Serviços Saúde 2015, 24, $277-286$. [CrossRef]

40. Barros, A.J.D.; Hirakata, V.N. Alternatives for logistic regression in cross-sectional studies: An empirical comparison of models that directly estimate the prevalence ratio. BMC Med. Res. Methodol. 2003, 3, 21. [CrossRef]

41. Pavão, A.L.B.; Werneck, G.L.; Campos, M.R. Autoavaliação do estado de saúde e a associação com fatores sociodemográficos, hábitos de vida e morbidade na população: Um inquérito nacional. Cad. Saude Publica 2013, 29, 723-734. [CrossRef]

42. Szwarcwald, C.L.; de Souza-Júnior, P.R.B.; Esteves, M.A.P.; Damacena, G.N.; Viacava, F. Socio-demographic determinants of self-rated health in Brazil. Cad. Saude Publica 2005, 21, 54-64. [CrossRef]

43. Ministério da Saúde, Secretaria de Atenção à Saúde, Departamento de Ações Programáticas Estratégicas. Política Nacional de Atenção Integral à Saúde da Mulher: Princípios e Diretrizes. 2004; p. 82. Available online: https://bvsms.saude.gov.br/bvs/ publicacoes/politica_nac_atencao_mulher.pdf (accessed on 4 March 2021).

44. Peres, M.A.; Masiero, A.V.; Longo, G.Z.; da Rocha, G.C.; Matos, I.B.; Najnie, K.; Oliveira, M.C.D.; Arruda, M.P.D.; Peres, K.G. Self-rated health among adults in Southern Brazil. Rev. Saude Publica 2010, 44, 901-911. [CrossRef]

45. Kaneva, M.; Gerry, C.J.; Baidin, V. The effect of chronic conditions and multi-morbidity on self-assessed health in Russia. Scand. J. Public Health 2018, 46, 886-896. [CrossRef]

46. Rocha, J.d.P.; Oliveira, G.G.; Neris, J.C.D.; Bós, A.M.G.; Bós, Â.J.G. Impacto clínico, socioeconômico e da autopercepção de saúde na funcionalidade de idosos. Geriatr. Gerontol. Aging 2017, 11, 124-132. [CrossRef]

47. Lima-Costa, M.F.; Cesar, C.C.; Chor, D.; Proietti, F.A. Self-rated health compared with objectively measured health status as a tool for mortality risk screening in older adults: 10-year follow-up of the Bambuí Cohort Study of Aging. Am. J. Epidemiol. 2012, 175, 228-235. [CrossRef]

48. Penning, M.J.; Wu, Z. Caregiver Stress and Mental Health: Impact of Caregiving Relationship and Gender. Gerontologist 2016, 56, 1102-1113. [CrossRef]

49. Wyman, M.F.; Shiovitz-Ezra, S.; Parag, O. Ageism in informal care network members of older women. Int. Psychogeriatr. 2019, 31, 1463-1472. [CrossRef]

50. Andrade, F.C.D.; Mehta, J.D. Increasing educational inequalities in self-rated health in Brazil, 1998-2013. PLoS ONE 2018, 13, e0196494. [CrossRef]

51. Sharma, A. Wealth and the health of older Black women in the United States. Health Promot. Int. 2019, 34, 1055-1068. [CrossRef]

52. Jradi, H.; Alharbi, Z.; Mohammad, Y. Self-rated health among Saudi women: Association with morbidity, lifestyle, and psychosocial factors. J. Epidemiol. Glob. Health 2018, 8, 183-188. [CrossRef]

53. Veromaa, V.; Kautiainen, H.; Juonala, M.; Rantanen, A.; Korhonen, P.E. Self-rated health as an indicator of ideal cardiovascular health among working-aged women. Scand. J. Prim. Health Care 2017, 35, 322-328. [CrossRef]

54. Warburton, D.E.R.; Bredin, S.S.D. Health benefits of physical activity: A systematic review of current systematic reviews. Curr. Opin. Cardiol. 2017, 32, 541-556. [CrossRef]

55. Rhodes, R.E.; Janssen, I.; Bredin, S.S.D.; Warburton, D.E.R.; Bauman, A. Physical activity: Health impact, prevalence, correlates and interventions. Psychol. Health 2017, 32, 942-975. [CrossRef]

56. Confortin, S.C.; Giehl, M.W.C.; Antes, D.L.; Schneider, I.J.C.; D'Orsi, E. Positive self-rated health in the elderly: A population-based study in the South of Brazil. Cad. Saude Publica 2015, 31, 1049-10460. [CrossRef]

57. Machado, V.d.S.S.; Valadares, A.L.R.; Costa-Paiva, L.S.d.; Moraes, S.S.; Pinto-Neto, A.M. Multimorbidity and associated factors in Brazilian women aged 40 to 65 years. J. N. Am. Menopause Soc. 2012, 19, 569-575. [CrossRef]

58. Tinetti, M.E.; Fried, T.R.; Boyd, C.M. Designing Health Care for the Most Common Chronic Condition-Multimorbidity. JAMA 2012, 307, 2493-2494. [CrossRef] [PubMed]

59. Muth, C.; Blom, J.W.; Smith, S.M.; Johnell, K.; Gonzalez-Gonzalez, A.I.; Nguyen, T.S.; Brueckle, M.-S.; Cesari, M.; Tinetti, M.E.; Valderas, J.M. Evidence supporting the best clinical management of patients with multimorbidity and polypharmacy: A systematic guideline review and expert consensus. J. Intern. Med. 2019, 285, 272-288. [CrossRef] [PubMed]

60. Ministério da Saúde. Plano de Ações Estratégicas para o Enfrentamento das Doenças Crônicas e Agravos não Transmissíveis. 2021; Volume 1,121p. Available online: http://bvsms.saude.gov.br/bvs/publicacoes/plano_enfrentamento_doencas_cronicas_ agravos_2021_2030.pdf (accessed on 18 November 2021). 